Case Report

Sridhara Narayana

Assistant Professor

Ramesh Teegala

Professor

Department of Neurosurgery, ASRAM Medical College, ELURU-534005, AP

Address for correspondence:

Prof. Ramesh Teegala

Department of Neurosurgery, ASRAM Hospital, ELURU

AndhraPradesh, INDIA-534005

Email: teegalar@gmail.com

Date submitted : 18/4/2019

Date accepted : 7/5/2019
Nepal Journal of Neurosciences 16:51-54, 2019

\section{Unusual Complication of the Foramen Magnum Decompression}

The pathophysiology of Chiari-Imalformation lies with the abnormal CSF flow across Foramen magnum and Foramen magnum decompression (FMD) restores this flow. However, recent data suggests that FMD itself can alter the CSF dynamics in an abnormal fashion resulting in raised intracranial pressure. We report such a case where FMD has led to the development of subdural hygroma and hydrocephalus. Patient was managed with VP shunt after a failed trial of re-exploration and burr hole drainage. The mechanism behind this complication is not clearly understood despite several hypotheses being proposed. Once established, management has to be individualized, based upon the clinical condition and location of CSF collection.

Key words: Foramen magnum decompression; Post foramen magnum decompression hydrocephalus; arachnoid tear; CSF dynamics.

foramen magnum with syrinx extending from C3 to D6 level (Fig-1). Patient has undergone FMD with standard removal of the $\mathrm{C} 1$ arch \& durotomy with arachnoid being left intact. However, a small arachnoid tear was noted intraoperatively. Lax duroplasty was done with synthetic dura graft. Patient was discharged in a stable condition, but he returned to us 10days later complaining severe headache. He was evaluated with MRI \& CT scan which revealed a well decompressed syrinx, and infratentorial and Right frontoparietal subdural hygroma with midline shift and CSF collection at the operative site (Fig-1). The patient was taken up for surgery and burr hole drainage of the subdural hygroma was done along with reexploration of the FMD site in the form of complete opening of the arachnoid, clipping the arachnoid to the surrounding dura and water tight duroplasty. Patient condition transiently improved only to deteriorate later in the form of altered sensorium within 2days of second surgery. CT brain was done which showed grossly dilated lateral ventricles with resolved subdural hygroma (Fig-2). VP shunt was performed and the patient recovered well. Post op CT showed well decompressed ventricles (Fig-2). 
Narayan et al
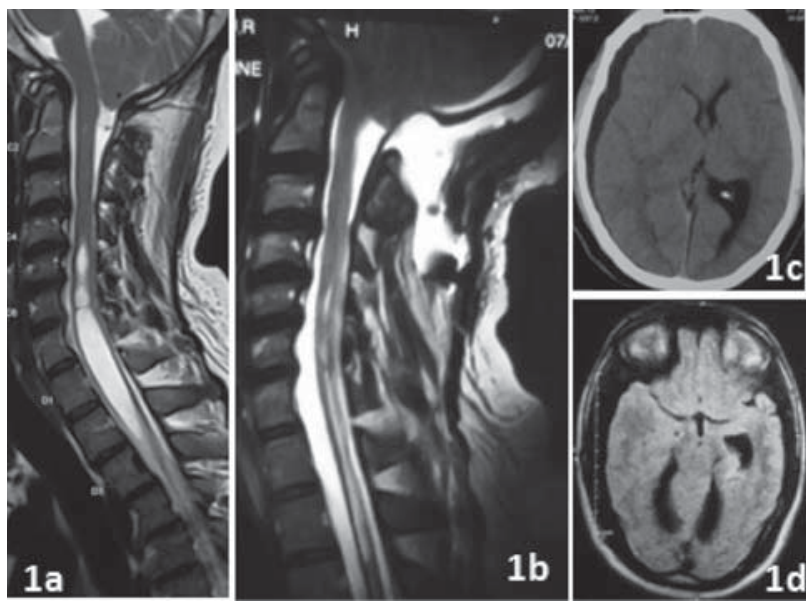

Figure 1: 1a - Pre-op MRI showing tonsillar descent with syrinx extending from C3 to D6 level. $1 b$ - post-op MRI showing well decompressed syrinx and CSF collection at the operative site. Persistent tight posterior fossa could be appreciated. 1c - post op CT plain brain revealing a right frontotemporoparietal subdural hygroma with midline shift and 1d - showing an infratentorial CSF collection.

\section{Discussion}

The manifestations of chiari-I malformation have been clearly identified to be due to the abnormal CSF flow across the foramen magnum. FMD has established itself as a standard surgical strategy in restoring the CSF flow and thereby alleviation of symptoms. Several techniques of FMD were proposed like durotomy leaving the arachnoid intact, durotomy with opening of arachnoid and adhesiolysis \pm sub pial tonsillar resection \& obex plugging, all the above with or without duroplasty. Even though the ideal technique of all these is still controversial, the complication rate with all these procedures is relatively low. It is clear now that any hydrocephalus present prior to FMD in a chiari-I patient has to be addressed first. However, the pathophysiology and management of hydrocephalus that develops following an FMD in these cases is still elusive.

Post FMD hydrocephalus incidence is low with Zakaria et al 16 reporting it as $8.7 \%$ and $18.5 \%$ by Duddy et al. ${ }^{5}$ This complication was commonly reported amongst patients who underwent durotomy without opening the arachnoid (in fact a small tear in the arachnoid was noted intraoperatively in most cases) nevertheless it was also identified in cases where arachnoid was widely opened. 7,9, 11-13 Review of the cases published till now is given in Table-1.

We think that hydrocephalus and extra axial CSF collection in these cases are not two distinct entities

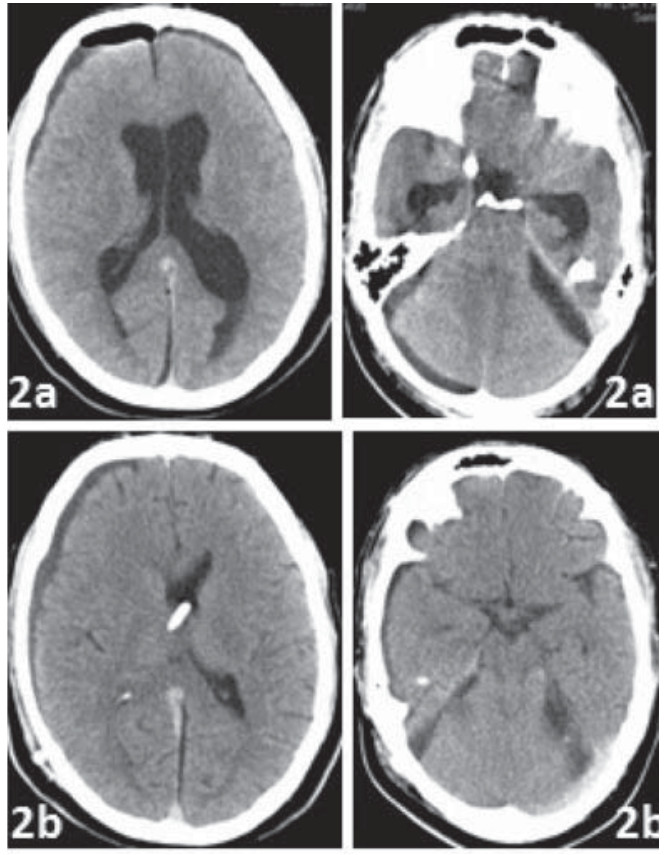

Figure 2: 2a-post op CT after burrhole drainage and reexploration, showing well drained subdural hygroma, with persistent hydrocephalus and infratentorial hygroma. $2 b$ - post op CT after VP shunt placement, revealing well decompressed ventricles and resolving infratentorial hygroma.

but rather are a continuum, where subdural hygroma formed initially leads to the development of obstructive hydrocephalus. ${ }^{2}$ The exact pathophysiology of development of extraaxial fluid collection following FMD is still not clear and various hypothesis were proposed by different authors (Table-2). Amongst all the most popular one is that of Ranjan \& Cast, a slit like opening in the arachnoid acts like a valve allowing only egress of CSF in to the subdural space under pressure and leading to formation of subdural hygroma. ${ }^{13}$ Even in our case there was an inadvertent arachnoid tear during the primary surgery, and hence during the second surgery we completely opened up the arachnoid and clipped it to the surrounding dura and a water tight duroplasty was done, along with burr hole drainage of supratentorial subdural hygroma. But there was no regression in hydrocephalus or infratentorial hygroma. If this above arachnoid valve mechanism were to be true then the hydrocephalus should have disappeared with wide arachnoid opening \& clipping it to the dura as proposed by Elton et al. ${ }^{6,13}$ Perrini et al reported similar findings and based on them proposed an alternative theory stating that a pseudomeningocele formation after FMD prevents normalization of CSF dynamics resulting in external hydrocephalus. ${ }^{11}$ Even in our case we noticed CSF collection at the operative site which was not large enough. This hypothesis along with 
Foaramen magnum decompression

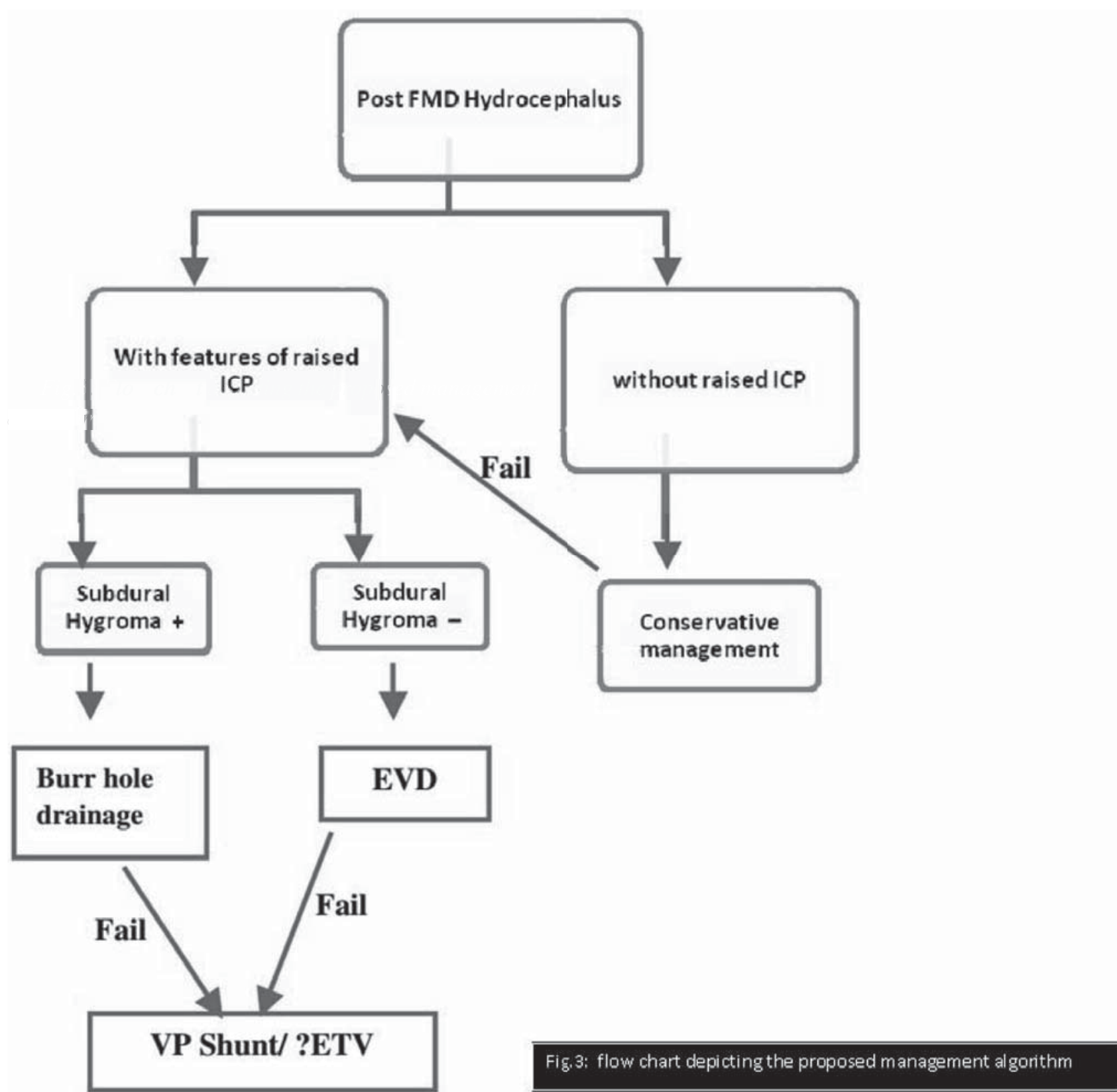

Fig.3: Flow chart depicting the proposed management algorithm

the statement of Iskander et al that surgery which yields symptomatic improvement also alters the CSF flow pattern in a complex manner, may explain the development of this complication in cases where Ranjan et al theory fails. ${ }^{8,13}$

From the literature, the management strategy for these cases is mostly a CSF diversion procedure rather than reexploration of the surgical site. In our case reexploration of the FMD was done without success which itself implies that the problem is neither localized to the FMD site nor related to the surgical technique but, rather is diffuse, related to the CSF flow dynamics, which essentially differs from patient to patient. However, Bahl et al has achieved resolution of infratentorial hygroma with reexploration and wide arachnoid opening, but these results should be interpreted with caution, since their patients had neither hydrocephalus nor supratentorial large subdural collections. $^{2}$

Asymptomatic patient with thin subdural hygroma or mild ventriculomegaly can be observed, since spontaneous resolution is not rare1. ${ }^{7,9,13,16}$ Hydrocephalus in association with prominent subdural collection does not usually respond to simple burr hole drainage of the subdural hygroma, necessitating an VP shunt. 3,11,12 For hydrocephalus alone, a temporary CSF diversion before 


\section{Narayan et al}

VP Shunt placement is recommended. ${ }^{6,15}$ An algorithm of management of these cases based up on all the reported cases till now is given in Figure - 3. Duddy et al proposed that ETV can be used as an alternative for VP Shunt in these cases but it needs to be evaluated further. ${ }^{5}$ Lastly, we agree that it is difficult to draw conclusions based on a few random case reports, however a prospective study with CSF flow analysis in these patients will give a better understanding of the pathophysiology, which might be possible since this complication is now being reported frequently.

\section{Conclusion}

The change in CSF flow dynamics resulting from FMD in chiari-I patients may not be always towards the normal spectrum, resulting in development of extraaxial CSF collections and or hydrocephalus. Pathophysiology behind this is not clearly understood despite several hypotheses being proposed. Once established, management has to be individualized, based upon the clinical status and location of CSF collection.

\section{References}

1. Arrese I, Kaen A, Lobato RD. Infratentorial hygroma. J Neurosurg 104 (5):856-7.2006

2. BahlA, Murphy M, Thomas N, Gullan R. Management of infratentorial subdural hygroma complicating foramen magnum decompression: a report of three cases. Acta Neurochir (Wien) 153 (5):1123-8,2011

3. Bahuleyan B, Menon G, Hariharan E, Sharma M, Nair S. Symptomatic posterior fossa and supratentorial subdural hygroma as a rare complication following foramen magnum decompression for chiari malformation type I. J Neurosurg 114 (2):510-3, 2011

4. Bosma JJ, Kumaran N, May PL. Cerebral oedema following EVD insertion for delayed hydrocephalus after foramen magnum decompresion in Chiari I malformation._Childs Nerv Syst 18 (9-10):474-7, 2002.

5. DUddy JC, Allcutt D, Crimmins D, O’Brien DF, Rawluk D, Sattar MT, Young S, Caird J. Foramen magnum decompression for Chiari I malformation: a procedure not to be underestimated. $\mathbf{B r} \mathbf{J}$ Neurosurgery 28 (3):330-4,2014.

6. Elton S, Tubbs RS, Wellons JC, Blount JP, Grabb PA, Oakes WJ. Acute hydrocephalus following a Chiari I decompression. Pediatr Neurosurg 36 (2):1014,2002.
7. Filis AK,Moon K, Cohen AR. Symptomatic subdural hygroma and hydrocephalus following Chiari I Decompression. Pediatr Neurosurg 45 (6):4258,2009

8. Iskandar BJ, Quingley M, Haughton VM. Foramen magnum cerebrospinal fluid flow chracteristics in children with Chiari I malformation before and after craniocervical decompression. J Neurosurg 101 (2 Suppl):169-78,2004.

9. Marshman LA, Benjamin JC, Chawda SJ, David KM. Acute obstructive hydrocephalus associated with infratentorial subdural hygroma complicating Chiari malformation Type I decompression. Report of two cases and literature review. J Neurosurg 103 (4):752-5,2005.

10. Menezes AH. Cerebral oedema following EVD insertion for delayed hydrocephalus after foramen magnum decompression in chiari I malformation. Childs Nerv Syst 18 (9-10):483-4,2002

11. Perrini P, Rawlinson A, Cowie RA, King. External hydrocephalus complicating craniocervical decompression for syringomyelia- Chiari I complex: Case report and review of literature. Neurosurg Rev 31 (3): 331-5,2008

12. Perrini P, Di Lorenzo N. Subdural fluid collection after decompression for Chiari malformation. J Neurosurg 114 (5): 1488-9, 2011.

13. Ranjan A, Cast IP. Symptomatic subdural hygroma as a complication of foramen magnum decompression for hind brain herniation (Arnold Chiari deformity). Br J Neurosurg 10 (3): 301-3,1996.

14. Sindou M, Chavez-Machuca J, Hashish H, Craniocervial decompression for chiari type I malformation, adding extreme lateral foramen magnum opening ans expansile duroplasty with arachnoid preservation. Technique and long term functional results in 44 consequitive adult casescomparison with literature data. Acta Neurochir (Wien) 144 (10):1005-19,2002

15. Tubbs RS, McGirt MJ, Oakes WJ. Surgical experience in 130 pediatric patients with Chiari I malformations. J Neurosurg 99 (2): 291-6,2003

16. Zakaria R, Kandasamy J, Khan Y, Jenkinson MD, Hall SR, Brodbelt A, Pigott T, MAllucci CL. Raised intracranial pressure and hydrocephalus following hind brain decompression for Chiari I malformation: a case series and review of literature. Br J Neurosurg 26 (4):476-81.2012 